FACULDADE DE CIÊ NCIAS ECONÔ MICAS DA UFRGS

REESTRUTURAÇÁ O DA PRODUÇÁ O AGRICOLA NO RIO GRANDE DO SUL, DE 1970 A 1996 E UMA ESTIMAÇȦ O PARA 2012 TIAGO WICKSTROM ALVES

A CRIMINALIDADE NA RECIAO METROPOLTANA DE SALVADOR JOSÉ CARRERA FERNANDEZ, LUIZ FERNANDO LOBO

COMPEIITIVIDADE INTERNACIONAL EM SOFTWARE: UM ESTUDO SOBRE A EXPERIÊNCIA DE FLORIANÓ POLIS HOVÉDO NUNES LINS

MODELOS DE ORGANIZAÇẢ O E REPARTIÇẢ O DE RENDAS NA CADEIA PRODUTIVA DO GÁS NATURAL.

HELder QUEIROZ PINTO Jú NIOR, RODOLFO TORRES dOS SANTOS

REGIMES MONETÁ RIOS E DIVIDA PÚ BLICA: UMA ANÁ LISE DE MECANISMOS ALTERNATIVOS DE COORDENAÇÃO MACROECONÓ MICA

manoel Carlos de Castro Pires

ECONOMIA DOS RECURSOS NATURAIS E SEUS INDICADORES DE ESCASSEZ: UMA QUESTÃ O DE SUSTENTABILIDADE ANDREA SALES SOARES DE AZEVEDO MELO

O ECOPROTECIONISMO AGRICOLA NA UNIĀ O EUROPEIA E SEUS POSSIVEIS IMPACTOS SOBRE A ECONOMIA BRASILEIRA Rodrigo daniel Feix, Clá udio R. Fóffano Vasconcelos

PADRÓ ES DE DESENVOLVIMENTO, FUNÇ Ó ES ESTATAIS E ENDIVIDAMENTO NO CAPITALISMO CONTEMPORÁNEO paulo Balanco, Eduardo Costa Pinto

A INTERNACIONALIZAÇÃO DO VAREJO A PARTIR DOS CASOS WAL-MART E CARREFOUR

Armando joảo dalla Costa

UMA ANÁ LISE ECONOMÉTRICA DO FUTEBOL BRASILEIRO ARI Francisco de Araujo JR, Clá udio D. SHIKIDA, LEONARDO M. MONASTERIO

O BRASIL E A ECONOMIA INTERNACIONAL: RECUPERAÇÃ O E DEFESA DA AUTONOMIA NACIONAL

RESENHA DE ALEXANDRE CÉ SAR CUNHA LEITE

REGIMES MONETÁ RIOS: TEORIA E A EXPERIÊNCIA DO REAL ResenHa de Fernando Ferrari Filho

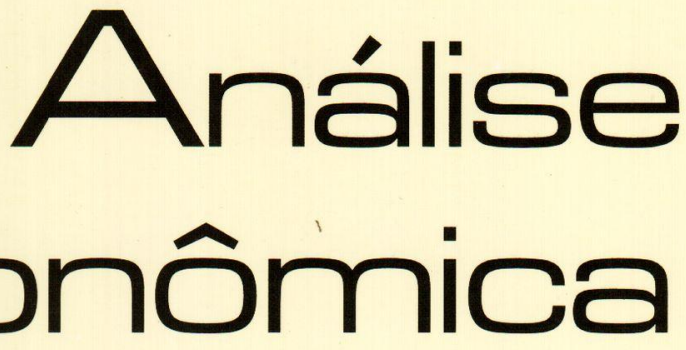


Universidade Federai. do Rio Grande do Sul Reitor: Prof José Carlos Ferraz Hemnemann

Facul dade de Cuéncias Economicas

Diretor: Prof. Gentil Corazza

Ceniro de Estudos f Prequisas Economicas

Diretor: Prof. Lovois de Andrade Miguel

Depariamenio de Crências Economicas

Chefe: Prof Ricardo Dathein

Departamento de Cîncias Coniábeis f A tuaria Chefe: Prof. Ceno Odilo Kops

Curso de Pós-Graduaçó em Economia

Coordenador: Prof. Fernando Ferrari Filho

Curso de Pos-Grainaça em Desenvolvimento RuRAI

Coordenador: Prof. Paulo Dabdab Waquil

Conseluo Eni tokial: André Moreira Cunha (UFRGS) Carlos G. A. Mielitz Netto (UFRGS), Carlos Henrique Hom (UFRGS). Eduardo A. Maldonado Filho (UFRGS). Eleutério F S. Prado (USP), Eugênio Lagemann (UFRGS), Fernando Cardim de Carvalho (UFRJ). Femando Ferrari Filho (UFRGS), Fernando de Holanda Barbosa (FGV/RJ), Flávio Augusto Ziegelmann (UFRGS), Flávio Vasconcellos Comin (UFRGS), Gentil Corazza (UFRGS), Giácomo Balbinot to Neto (UFRGS), Gustavo Franco (PUC/RJ) Hélio Henkin (UFRGS), Jan A. Kregel (UNCTAD), João Rogério Sanson (UFSC), Joaquim Pinto de Andrade (UnB), Júlio César Oliveira (UFRGS), Luiz Estrella Faria (UFRGS), Luiz Paulo Ferreira Nogueról (UFRGS), Marcelo S Portugal (UFRGS), Maria Alice Lahorgue (UFRGS), Octávio Augusto Camargo Conceicão (UFRGS), Paul Davidson (University of Tennessee), Paulo D. Waquil (UFRGS), Pedro C. D. Fonseca (UFRGS), Philip Arestis (University of Cambridge), Ricardo Dathein (UFRGS) Ronald Otto Hillbrecht (UFRGS), Sabino da Silva Porto Jr (UFRGS), Sérgio M. M. Monteiro (UFRGS), Stefano Florissi (UFRGS) e Werner Baer (University of IIIinois at Urbana - Champaign)

Comissão Emroniai: Eduardo Augusto Maldonado Filho, Fernando Ferrari Filho, Hélio Henkin. Marcelo Savino Portugal, Paulo Dabdab Waquil e Sérgio Marley Modesto Monteiro.

EnIrok: Sérgio Marley Modesto Monteiro

Ediror Adjun ro: Hélio Henkin

Secretário: Emerson Douglas Neves

REVISÃo DE IEX ros: Vanete Ricacheski

Emioração: Núcleo de Editoração e Criação da

Gráfica da UFRGS - Janaína Horn e Junia Saedt

Fundador: Prof Antonio Carlos Santos Rosa
Os materiais publicados na revista Análise Econômica são da exclusiva responsabilidade dos autores. É permitida a reprodução total ou parcial dos trabalhos, desde que seja citada a fonte. Aceita-se permuta com revistas congêneres. Aceitam-se, também, livros para divulgacão, elaboraça de resenhas e recensões Toda correspondência: material para publicação (vide normas na terceira capa), assinaturas e permutas devem ser dirigidos ao seguinte destinatário:

Prof. Sérgio Marley Modesto Monteiro Revista Andilse Económica - Av. João Pessoa, 52 CEP 90040-000 PORTO ALEGRE - RS, BRASIL Telefones: (051) $33163513 / 33164164$

Fax: (051) 33163990 - E-mail: rae@vortex ufrgs.br

A Revista Análise Econômica agradece a colaboração dos pareceristas do número 43, abaixo relacionados:

Adalmir Antonio Marquetti

André Moreira Cunha

Carlos José Caetano Bacha

Carlos Mielitz. Netto

Clailton Ataídes de Freitas

Claudio Roberto Fóffano Vasconcelos

Eduardo Ernesto Filippi

Eduardo Pontual Ribeiro

Eleuterio Fernando da Silva Prado

Fernando J Cardim de Carvalho

Fernando Augusto Mansor de Mattos

Fernando Ferrari Filho

Flávio Tosi Feijó

Flavio Vilela Vieira

Francisco Paulo Cipolla

Gentil Corazza

Gíacomo Balbinotto Neto

Helio Henkin

Jefferson Andronio Ramundo Staduto

João de Deus Sicsú Siqueira

José Carrera Fernandes

Leonardo Monteiro Monasterio

Luís Fernando de Paula

Luis Roberto Nascimento

Manoel Carlos de Castro Pires

Octavio Augusto Camargo Conceição

Patrízia Raggi Abdallah

Robson Antonio Grassi

Ronald Otto Hilbrech

Tiago Wickstrom Alves

Tito Belchior Silva Moreira

Análise Econônica

Ano 23, n ${ }^{\circ} 44$, setembro, 2005 - Porto Alegre

Faculdade de Ciências Economicas, UFRGS, 2000

Periodicidade semestral, março e setembro

1. Teoria Econômica - Desenvolvimento Regional -

Economia Agrícola - Pesquisa Teórica e Aplicada -

Periódicos. I.. Brasil

Faculdade de Ciências Econômicas,

Universidade Federal do Rio Grande do SuI

CDD 330.05

CDU $33(81)(05)$ 


\section{Regimes monetários e dívida pública: uma análise de mecanismos alternativos de coordenação macroeconômica}

Resumo: A dívida pública brasileira tem sido grande objeto de análise devido ao seu comportamento ascendente após a implementação do Plano Real. Este artigo argumenta que a coordenação macroeconômica representa um mecanismo capaz de estabilizar a trajetória da relação divida-PIB. Em especial, mostra-se que a alteração da estrutura de vencimentos e a adoção de controles de capitais podem contribuir para o alcance deste objetivo assim como a indexação via inflação. Além disto, o superávit primário pode não ser o melhor instrumento para a estabilidade da dívida pública.

Palavras-chave: dívida, estrutura de indexação, controles de capitais.

Abstract: Brazilian public debt has been growing since real plan implementation. This paper discusses macroeconomic coordination as a principal feature for the stability of the Brazilian public debt. The results shows that maturity and capital controls play a principal role for this aim as well as inflation indexation. Besides, primary surplus may not be the best instrument for public debt stability.

Keywords: debt, indexation estructure, capital controls.

JEL Classification: E62, E63, H63.

\section{Introdução}

O Plano Real, que se iniciou em julho de 1994, marcou uma nova era na política macroeconômica brasileira. A partir de sua implementação, a política macroeconômica redirecionou seu foco ao colocar o combate à inflação como meta principal. Esse combate se caracterizou por medidas de ajuste estrutural, notadamente a liberalização comercial, e por medidas conjunturais via elevadas taxas de juros e manutenção de uma taxa de câmbio semifixa e em patamar valorizado (pelo menos até janeiro de 1999). ${ }^{1}$

Uma característica desse período foi a abrupta elevação da dívida líquida do setor público. Este comportamento se deve, em gran-

\footnotetext{
- Doutorando em Economia da Unb e Técnico em Pesquisa do IPEA.

1 Após janeiro de 1999, o regime de câmbio se tornou flutuante e adotou-se o regime de metas para a inflação como âncora nominal.
} 
de parte, a três fatores principais: (i) o elevado pagamento de juros durante o período, (ii) os ajustes patrimoniais realizados durante os dois governos do ex-presidente Fernando Henrique Cardoso e a reestruturação das dívidas com os estados e; (iii) o prazo de vencimentos da dívida mobiliária que é extremamente curto e concentrado se tornando um potencial problema em períodos de crises financeiras.

Os elevados pagamentos realizados devido à rolagem de dívida foram em sua maioria devidos à indexação de títulos da dívida pública à taxa selic. ${ }^{2}$ Uma tentativa de amenizar os impactos da taxa de juros sobre a dívida foi sua indexação à taxa de câmbio, que foi mantida em patamar valorizado. Tal estratégia se mostrou equivocada, pois o governo não conseguiu controlar a taxa de câmbio devido à liberalização financeira que promoveu de forma que, após uma crise de confiança, uma fuga de capitais impossibilitou a manutenção do regime.

A realização de ajustes patrimoniais se deveu à necessidade de reconhecer dívidas que não eram incorporadas ao passivo da federação. A incorporação de tal ajuste em certo grau é imprevisível dado, entre outros fatores, a falta de transparência no seu processo de reconhecimento. ${ }^{3}$ Por outro lado, a estruturação da dívida dos estados deveria ser considerada um ajuste once for all já que novas negociações poderiam causar o problema de risco moral além de afetar negativamente as contas da União (VERSIANI, 2003).

O último item, referente à concentração de prazos da dívida pública, representa um enorme desafio para o tesouro brasileiro. De acordo com Guidotti e Kumer (1991), existem dois motivos para a concentrada distribuição dos prazos da dívida pública: a fragilidade das contas públicas e as expectativas em relação à inflação. Entretanto, estas condições não mais vigoram para a economia brasileira (pelo menos no período recente de 1999 a 2004) e, não obstante, este frágil arranjo se mantém parcialmente intacto. ${ }^{4}$

A necessidade de se alterar a estrutura de vencimentos e da escolha do melhor indexador para os títulos públicos representa o problema de administração macroeconômica. A dívida pública mobiliária é o principal componente da dívida líquida do setor público

\footnotetext{
2 Ainda que até 1998 o câmbio representasse uma âncora para o nível de preços, este era sustentado por taxas de juros elevadas.

3 Para uma análise mais detalhada do ajuste patrimonial brasileiro recente ver, Pego Filho e Pinheiro (2004)

4 Barcinski (1999) mostrou que, após a derrubada do regime de alta inflação, o Brasil conseguiu alongar sua estrutura de prazos. Contudo, este resultado é pouco expressivo dado que a melhora não foi substancial e ficou aquém das necessidades brasileiras, conforme o próprio autor reconhece.
} 
e representa o componente passível de projeção, com maior grau de confiabilidade. ${ }^{5}$ Além disto, o governo tem ao seu dispor alguns instrumentos de curto prazo para administrá-la (a taxa de juros, taxa de câmbio, superávit primário, etc.).

Diante desta perspectiva, os fatores (1) e (3) são os que melhor podem colaborar com a estabilidade da dívida líquida do setor público. Tal reconhecimento fez surgir inúmeras propostas para alterar a composição de indexação e melhorar a estrutura de vencimentos da dívida líquida do setor público e, assim, estabilizar a trajetória da relação dívida-PIB.

Sobre o indexador da dívida, Bevilaqua e Garcia (2002) propuseram que tais títulos sejam ligados a um índice de inflação. ${ }^{6} \mathrm{Na}$ mesma linha, De Mendonça (2004) afirma que este tipo de indexador reduziria o custo de coordenação macroeconômica, pois um banco central comprometido com a busca da estabilidade de preços não causaria maiores custos para a autoridade fiscal.

No caso da estrutura de vencimentos da dívida, o problema é um pouco mais desafiador. Conforme já mostraram Calvo e Guidotti (1990), a concentração de prazos se torna um convite para as crises. Quando o vencimento da divida é concentrado em poucas datas, o governo pode ter problemas em rolar essa dívida, pois pode fazê-lo em condições desfavoráveis.

Esta estrutura de vencimentos pode ser explicada (1) pela ausência de oferta, por parte do Banco Central do Brasil, de títulos de longo prazo em que o prêmio de risco a ser pago é mais elevado, ou (2) pela não aceitação dos agentes privados em carregar títulos de prazo longo.

Contudo, o Banco Central do Brasil em várias ocasiões tentou ofertar títulos de longo prazo, mas não conseguiu demanda por esses produtos. Quando conseguia demandante, o prêmio de risco exigido tornava a operação proibitiva (BARCINSKI, 1999). O elevado grau de preferência pela liquidez, exibido pelos agentes privados, tem concentrado os vencimentos da dívida mobiliária em prazos curtos, o que torna a rolagem da dívida uma fonte desestabilizadora em potencial.

Assim, destes três fatores que contribuíram para a ascensão da relação dívida-PIB, o governo pode diretamente atuar (ainda que de

5 Para corroborar esta afirmação, vale notar que em alguns momentos do período de análise a dívida mobiliária ultrapassou a dívida líquida do setor público (VERSIANI, 2003).

6 De acordo com os autores, o governo brasileiro tem evitado utilizar índices de inflação com o temor de que isto alimente o processo inflacionário. 
forma limitada) sobre a estrutura de indexação, pois os ajustes patrimoniais possuem baixa previsibilidade e a concentração dos vencimentos depende de um fator que não é passível de controle, no caso, a preferência pela liquidez dos agentes privados.

O objetivo deste artigo é contribuir no estudo realizado por Oreiro e Paula (2003), ao analisar como diferentes regimes de política macroeconômica podem afetar a trajetória da dívida e estabilizála. Para tanto, o artigo conta com quatro seções, além desta introdução. A próxima seção desenvolve uma equação de dinâmica para a dívida com indexadores alternativos.

A terceira seção mostra quais regimes de política macroeconômica podem estabilizar a trajetória da dívida. A quarta seção utiliza a equação da dinâmica da dívida derivada anteriormente para testar qual tipo de política pode ser implementada a fim de estabilizar a dívida pública.

$\mathrm{Na}$ última seção, conclui-se que a estabilidade da dívida está atrelada ao regime de política macroeconômica. A utilização do superávit primário para a estabilização da dívida pública é apenas um instrumento, que pode não ser tão eficaz como a redução da taxa de juros ou a indexação da dívida a instrumentos menos voláteis como índices de preços. Em especial, a alteração da estrutura de indexação e a utilização de controles de capitais podem estabilizar a dívida sem que seja necessário utilizar-se de ajustes considerados recessivos, como a elevação do superávit primário realizado nos últimos anos.

\section{A dinâmica da dívida: analisando o impacto de indexadores alternativos}

O déficit do governo no período $t$ pode ser expresso como o déficit primário $(G-T)$ mais o pagamento que ele incorre sobre o estoque da sua dívida $(B)$ decorrente de períodos anteriores. Supõese, neste caso, que existe uma parcela da dívida indexada à taxa de juros nominal $(r)$ e uma outra parcela indexada à taxa de câmbio spot (e) (no caso brasileiro o dólar). Este déficit pode ser financiado com a emissão de títulos $(\dot{B})$ ou com a emissão de moeda $(\dot{M})$ por parte do banco central.

$$
(G-T)+\alpha \mathrm{rB}+(1-\alpha) e B=(\dot{B})+(\dot{M})
$$

onde $\alpha$ representa o peso que cada indexador possui sobre o estoque da dívida e o ponto significa a derivada no tempo da variável. 
Definindo $b=\mathrm{B} / \mathrm{Y}$, a relação dívida - PIB, e diferenciando no tempo obtém-se: $\dot{b}=\frac{B}{Y}-B \dot{Y} / Y^{2}$

Arranjando os termos: $\dot{B}=\dot{b} Y+b \dot{Y}$. Daí,

$$
(\mathrm{G}-\mathrm{T})+[\alpha(\mathrm{r}-\mathrm{e})+\mathrm{e}-\mathrm{x}] \mathrm{B}=\dot{b} \mathrm{Y}+(\dot{M})
$$

onde $x$ representa a taxa de crescimento da economia.

Ao dividir-se (2) pelo PIB, definindo $\dot{M} / /$ como $\dot{m}$, e arranjando os termos obtidos chega-se à equação de dinâmica da dívida:

$$
\dot{b}=(g-t)+[\alpha(r-e)+e-x] b+\dot{m}
$$

Esta equação afirma que o endividamento depende do déficit primário, das receitas de senhoriagem e do próprio estoque da dívida que pode contribuir positivamente ou negativamente dependendo do sinal do termo $\alpha(r-e)+e-x$. Este termo contribuirá positivamente se as variáveis que indexam a dívida forem mais relevantes que a taxa de crescimento do PIB.

A explicação econômica para este termo se dá pelo fato de que, quando o câmbio se eleva, a dívida se eleva, porém deve-se desconsiderar o termo que é atribuído à taxa de juros e vice-versa. Assim, o termo $\alpha$ mede a importância que o regime de política macroeconômica possui na dinâmica da dívida. Por exemplo, em um regime de câmbio fixo, a dívida pode ser indexada ao câmbio e a taxa de juros pode realizar o equilíbrio externo. ${ }^{7}$ Em um regime de metas inflacionárias dever-se-ia buscar um terceiro indexador, pois, nesse regime, a taxa de juros visa a uma meta de inflação e o câmbio é flutuante. Em um choque de oferta estas duas variáveis teriam efeitos negativos sobre a dinâmica da dívida.

7 A questão que se revela importante, neste caso, é sob quais condições este regime cambial é crível. Se em um mundo com mobilidade de capitais ou com a adoção de controle de capitais. 


\section{A dinâmica da dívida sobre mecanismos monetários alternativos: uma análise de estabilidade}

\subsection{Equilibrio externo e choques macroeconômicos}

O primeiro mecanismo de gestão monetária a ser considerado por esta análise é a busca do equilibrio externo. Neste sentido, o banco central impõe a seguinte regra:

$$
\mathrm{dr} / \mathrm{dt}=\chi\left(r-r^{*}-\dot{e}-\theta\right)
$$

onde $r^{*}$ é a taxa de juros internacional, $\dot{e}$ é a taxa esperada de desvalorização cambial, $\theta$ é o risco de default e $\chi$ é a velocidade com a qual o banco central ajusta a política monetária. Em um regime de câmbio fixo (ou semifixo) e tomando as expectativas como dadas, $\dot{e}$ é constante (e próximo de zero), e a taxa de juros equilibra o rendimento dos ativos vis-à-vis a taxa de juros internacional e o risco de default.

Dois cenários podem ser construídos a partir deste desenho macroeconômico e que dependem do parâmetro $\alpha$. Quando $\alpha$ é próximo de 1, a dinâmica da dívida responde em sua grande maioria aos movimentos da taxa de juros e à tentativa por parte do banco central em adequar o ambiente interno ao externo. Quando $\alpha$ tende a zero, a dívida é em grande parte indexada à taxa de câmbio e em um regime de câmbio fixo, a estabilidade da dívida fica garantida.

A análise de estabilidade pode ser realizada a partir da matriz jacobiana $(J)$ do sistema dado pelas equações (3) e (4), para as duas hipóteses:

(i)- $\alpha \rightarrow 1$. Traço $(J)=\alpha(r-e)+e-x+\chi \operatorname{eDet}(J)=(\alpha(r-e)+e-x) \chi$; ambos maiores que zero, visto que a economia brasileira tem apresentado elevadas taxas de juros. Este resultado indica que as raízes do sistema são reais, mas o sistema é instável.

(ii) - $\alpha \rightarrow 0$. Traço $(J) \rightarrow e-\chi+\chi \operatorname{e} \operatorname{Det}(J)=(e-\chi) \chi$; ambos menores que zero, indicando que este sistema é estável e suas raízes são complexas.

No caso da estratégia (i), a presença de choques externos poderia inviabilizar a estabilidade da dívida pública sendo necessário um ajuste fiscal por meio de elevação do superávit primário. 
Na manutenção de um regime de câmbio flutuante, a estratégia (2) também seria frágil na presença de choques externos dado que $e$ poderia variar muito (o que acontece no caso brasileiro). Neste cenário, elevações da própria taxa de juros podem estar associadas a desvalorizações cambiais o que cria uma trajetória perversa sobre a dívida.

Ainda que se atenue, no regime de flutuação cambial, a pressão sobre a taxa de juros, a experiência brasileira tem mostrado que esta se manteve muito elevada, o que indica uma estratégia de coordenação macroeconômica instável. Este resultado independe da forma como a dívida pública está sendo indexada: via taxa de câmbio ou via taxa de juros, ou seja, independe do valor de $\alpha$.

Uma possibilidade é a de que o banco central atue regulando a conta de capital. De acordo com Tamirisa (2004), a Malásia conseguiu reduzir a taxa de juros com a introdução de restrições à saída de capital e elevar a taxa de juros com a introdução de restriçōes à entrada. Assim, o banco central pode adotar uma regulação financeira com vistas a reduzir a taxa interna de juros ou desvinculandoa da paridade descoberta, adotando a seguinte regra:

$$
\mathrm{dr} / \mathrm{dt}=\chi\left(r-r^{*}-\dot{e}-\theta-\lambda r e+y r s\right)
$$

onde re e rs representam restrições à entrada e à saída, respectivamente, e $\lambda$ e $\gamma$ são parâmetros positivos.

Se a taxa de juros é sensível à regulação financeira, então o banco central pode estabilizar a dívida pública, mesmo na presença de choques externos. Este resultado reduz a importância de ajustes fiscais que comprometem a eficiência do setor público, ou mesmo, o estado da economia. Neste caso, reduz-se a pressão sobre a taxa de juros tornando o traço da matriz menor que zero, estabilizando o arranjo. Se os parâmetros não são muito sensíveis, o banco central poderia endogenizar a regulação financeira e fazê-la função do próprio estoque da dívida: ${ }^{8}$

8 A idéia de regular de maneira discricionária a conta de capital pode apresentar alguns problemas, pois afeta a previsibilidade e as expectativas de longo prazo dos agentes econômicos. O que tem sido proposto, em geral, é um arcabouço bem definido de regulação financeira com vistas à estabilização macroeconômica sem prejudicar as decisões micro. Uma destas propostas pode ser encontrada em De Paula, Oreiro e Silva (2003). 


$$
\mathrm{dr} / \mathrm{dt}=\chi\left(r-r^{*}-\dot{e}-\theta-\lambda r e(b)+\gamma r s(b)\right)
$$

onde $\partial r e / b<0$ e $\partial r e / \partial b>0$.

Este tipo de mecanismo pode tornar os parâmetros sensíveis o suficiente para estabilizar a trajetória da divida pública. ${ }^{9}$

3.2 Metas inflacionárias, equilibrio externo e choques macroeconômicos

O segundo mecanismo de gestão monetária a ser analisado é o regime de metas inflacionárias. Neste regime, o banco central regula a taxa de juros de acordo com o desvio da inflação corrente em relação a sua meta:

$$
\mathrm{dr} / \mathrm{dt}=\phi\left(\pi-\pi^{*}\right)
$$

onde $\pi$ é a taxa de inflação corrente e $\pi^{*}$ é a meta para inflação.

Nesta estratégia, o regime cambial deve ser o flutuante e a equação para a inflação pode ser dada por:

$$
\pi=\mu \pi_{D}+(1-\mu)\left(\pi_{F}+\dot{e}\right)
$$

onde $\pi_{\mathrm{D}}$ é a taxa de inflação dos bens que não têm componentes importados e $\pi_{F}$ é a inflação dos bens que possuem insumos importados .

Nesta estratégia, a taxa de câmbio é a responsável por realizar ajustes entre o setor interno e o setor externo da economia. Desta forma, (4) se altera para:

$$
\mathrm{dr} / \mathrm{dt}=\delta\left(r-r^{*}-\dot{e}-\theta\right)
$$

onde $\delta$ é a velocidade de ajuste do mercado de capitais.

9 Pode-se argumentar que o câmbio flutuante já é capaz de realizar o equilíbrio externo. Contudo a experiência brasileira tem mostrado que o Banco Central reage com a taxa de juros para evitar o excesso de volatilidade no mercado de câmbio (SICSÚ, 2002). 
Assim, um choque na taxa internacional de juros, ou mesmo no risco de default, em um regime de câmbio flutuante, eleva a taxa de câmbio. Este movimento tem dois efeitos, o primeiro de elevar parte da dívida pública e o segundo o de elevar um dos componentes da inflação. O banco central eleva a taxa de juros para controlar a inflação acelerando a trajetória da dívida. Neste caso, duas soluções seriam viáveis: (i) regular a entrada e saída de capitais para desvincular choques externos da taxa de juros ou da taxa de câmbio; ou (ii) alterar a estrutura de indexação da dívida para uma terceira variável.

A primeira solução dependeria novamente de os parâmetros serem suficientemente sensíveis. A segunda estratégia busca desvincular a política fiscal de variáveis propensas a choques de curto prazo. Conforme apontado, alguns autores têm proposto a indexação da dívida à taxa de inflação. Assim, na presença de choques externos, a elevação da taxa de juros e o controle da taxa de inflação não causariam efeitos sobre a política fiscal. Esta poderia, ainda, ser contracíclica em momentos de choques de oferta.

\section{Simulações para a trajetória da relação dívida-PIB}

O estudo da trajetória da dívida pública será realizado com base na equação de dinâmica da dívida (3) de acordo com os diferentes regimes de política macroeconômica. O objetivo desta seção é mostrar quais tipos de arranjos são mais adequados para gerar uma trajetória estável da relação dívida-PIB.

A idéia é que esta relação evolui ao longo do tempo e, a partir de um certo momento, ocorre um choque internacional. A taxa internacional de juros é elevada, a percepção de risco se eleva e ocorre uma fuga de capitais que aumenta a expectativa de desvalorização. A partir daí, o ajuste macroeconômico pode se dar via: (i) elevação do superávit primário (cenário I), (ii) alteração da estrutura de indexação (cenário II); (iii) introdução de controle de capitais (cenário III), e (iv) alteração da estrutura de indexação e introdução de controle de capitais (cenário IV).

A Tabela 1 mostra os valores assumidos para as simulações. A segunda coluna mostra o cenário básico além das condições iniciais de que a dívida se iniciou em $60 \%$ do PIB e que o câmbio se situava em 2,9 R \$/US\$. Com este cenário, fez-se a hipótese de que no oitavo período ocorreu um choque externo dado pela mudança das variáveis da terceira coluna (Tabela 1). A política macroeconômica reagia no mesmo período e era mantida indefinidamente. As variáveis que 
causaram os choques retornaram para seu patamar inicial dois períodos após a sua ocorrência.

Foram feitas duas exceções a esta regra. No caso da taxa de câmbio, a experiência brasileira mostrou que, em momentos de crise, o câmbio se desvaloriza excessivamente e depois retrocede para um patamar mais elevado que o anterior. Assim, após a desvalorização de $45 \%$ em dois períodos, a taxa de câmbio se valoriza em $20 \%$ durante três períodos e depois retorna ao patamar pré-crise.

A segunda exceção foi o parâmetro $\alpha$ (que mensura a proporção de títulos indexados à taxa de juros). Não é razoável imaginar que o governo conseguisse elevar este parâmetro de $70 \%$ para $95 \%$ de uma única vez que não seja de forma compulsória. A hipótese é que o governo altera para $75 \%$ (durante um período), $80 \%$ (durante dois períodos), $85 \%$ (durante dois períodos), $90 \%$ (durante dois períodos) e $95 \%$ daí em diante. Os resultados estão expressos no Gráfico 1.

Tabela 1 - Valores para a simulação da trajetória da relação dívida-PIB

\begin{tabular}{c|c|c|c}
\hline Variáveis & Cenário Básico (\%) & Choques (\%) & Resposta Macroeconômica \\
\hline$(g-t)$ & 3,8 & - & 4,25 \\
$x$ & 3,5 & 2,0 & - \\
$r^{*}$ & 1,0 & 2,5 & - \\
$\dot{e}$ & 4,0 & 45,0 & - \\
$\theta$ & 4,0 & 9,0 & 0,3 \\
$r e$ & 0 & - & 0,7 \\
$r s$ & 0 & - & $0,75-0,95$ com acréscimos \\
$\alpha$ & 70,0 & - & graduais de 0,5 \\
$\dot{m}$ & 10,0 & - & - \\
\hline
\end{tabular}

Para as variáveis re e rs, foi feita a hipótese de que existia mobilidade plena de capitais e que seriam introduzidos alguns controles no período de crise e que tais controles seriam mantidos. Crucial para a simulação as sensibilidades impostas $(0,3$ e 0,6 respectivamente com 1 significando controle total da conta de capital). A explicação para estes números é que a Malásia reforçou os controles pela saída muito mais que pela entrada. Sobre a estrutura de indexação foi feita a hipótese de que o governo a altera lentamente.

O gráfico mostra que a trajetória da dívida é levemente ascendente. As trajetórias começam a divergir após a introdução do choque, e esta divergência depende da resposta de política macroeconômica implementada pelo governo. 


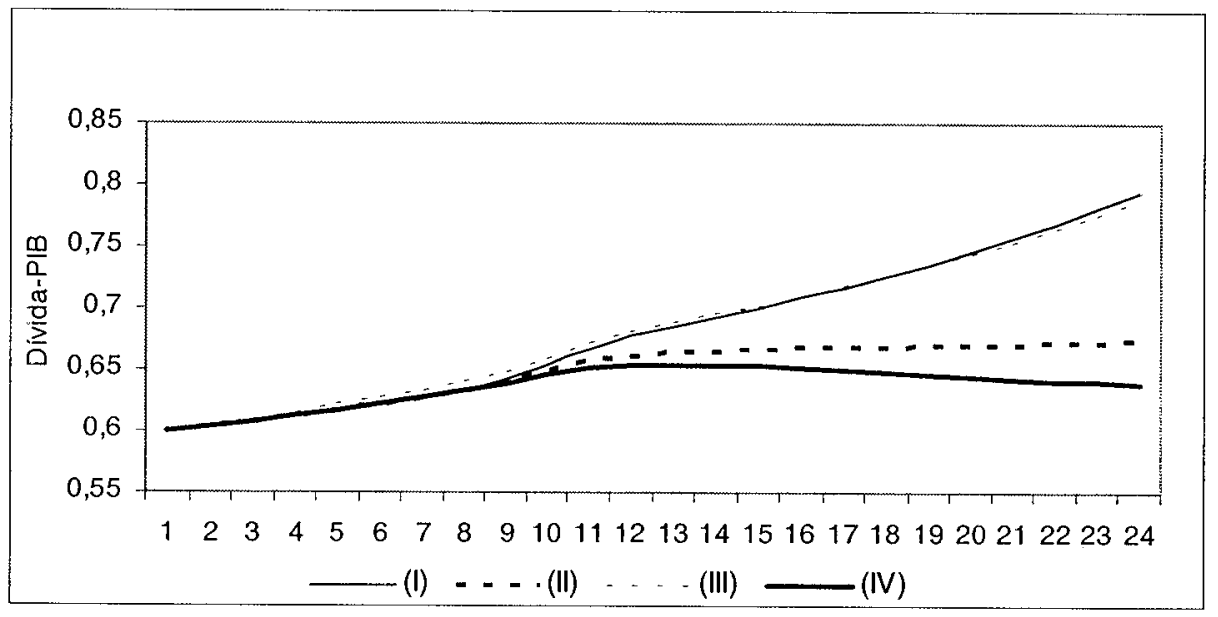

Gráfico 1: Evolução da relação dívida-PIB com diferentes respostas a choques externos.

O cenário (I) é o caracterizado pelo ajuste no superávit primário. Após a introdução do choque e a elevação do superávit primário, a trajetória da dívida se mantém ascendente e a mudança na inclinação, no período 12 , se deve ao fim do choque externo. Entretanto, a trajetória se mantém ascendente. A inelasticidade da dívida pública ao superávit primário pode ter se dado pelo fato de que, para este tipo de choque, a resposta macroeconômica pode ter sido insuficiente.

O cenário (II) se refere à mudança na estrutura de indexação abandonando a indexação via taxa de câmbio. Percebe-se que esta estratégia pode estabilizar a relação divida-PIB após o fim do choque. O choque produz uma elevação no nível da dívida, mas sua trajetória é estável.

No cenário (III), o governo introduz controle de capitais. A trajetória da relação dívida-PIB é ascendente, mas, após o período 18 , ela começa a divergir do cenário (I) representando um mecanismo levemente superior. $\mathrm{O}$ cenário (IV) introduz um mix entre controle de capitais e alteração da estrutura de indexação. Esta estratégia resulta em uma trajetória descendente. Este último resultado independe da necessidade de ajustes fiscais.

Diante da proposta de indexação da dívida mobiliária à taxa de inflação, simularam-se algumas séries de taxa de inflação com base na equação (7). Os dados foram simulados da seguinte forma:

- geraram-se dez séries para a taxa de inflação doméstica a partir de uma distribuição normal com média quatro e variância 1,21. A razão para 
estes valores é que o Banco Central tem como meta de longo prazo uma taxa de inflação de $4 \% \cdot{ }^{10}$ Além disto, as bandas superiores e inferiores são de $2 \%$. O desvio padrão de 1,21 mantém a taxa de inflação dentro deste intervalo com confiança de $95 \%$;

- a taxa de inflação externa foi simulada a partir de um passeio aleatório com valor inicial igual a quatro e geraram-se dez séries de ruído branco. Obtiveram-se, portanto, dez séries de inflaçāo externa; ${ }^{11}$

- somaram-se as séries de inflação doméstica e inflação externa com pesos iguais a 0,5 para cada série, gerando dez séries de taxa de inflação. A escolha destes pesos teve impacto desprezível sobre os resultados. Daí optou-se pelo exame de apenas uma estrutura de pesos para a inflação para efeitos de simplificação.

A partir da criação destas séries, simulou-se a trajetória da dívida com as mesmas hipóteses iniciais (dispostas na Tabela 1). A exceção foi a introdução da taxa de juros interna na equação, substituindo as variáveis que a igualam na teoria da paridade descoberta dos juros. Esta escolha se deve ao fato que grande parte do ajuste externo é feita pela taxa de câmbio. A taxa de juros acaba por equilibrar a economia quando o câmbio começa a causar impactos sobre o nível de preços.

As dez séries geradas foram simuladas diante de diferentes pesos para os indexadores (taxa de juros e inflação) com valores para $\alpha=0,90 ; 0,70 ; 0,50 ; 0,30$ e 0,10 . Os resultados (Gráfico 2) mostram que a trajetória da dívida é descendente para diferentes pesos (diferentes $\alpha$ 's). Os resultados, em geral, mostraram que, quanto maior o peso dado à dívida indexada à taxa de inflação, maior era o decréscimo da dívida pública.

Como tal estrutura de endividamento pode responder a choques de curto prazo? Para responder a esta pergunta foi simulada uma taxa de inflação mais longa, mas com a mesma estrutura das anteriores. Quando a taxa da inflação se desviar da meta, o banco central reage elevando a taxa de juros até que a taxa de inflação retorne à meta. A regra de política monetária foi imposta de forma que, sempre que a inflação se desviava da meta, a taxa de juros se desviava com um parâmetro igual a 1,4. Este parâmetro foi encontrado por Minella et alii (2002) ao estimar a função de reação do Banco Central do Brasil.

1o Apesar de esta meta não ter sido feita publicamente, sempre que a economia brasileira se refaz de um choque adverso, o Banco Central estipula um cronograma de metas para a inflação que se estabiliza em torno de $4 \%$.

II A idéia desta simulação é que o ruído branco poderia captar os choques provenientes da taxa de câmbio 


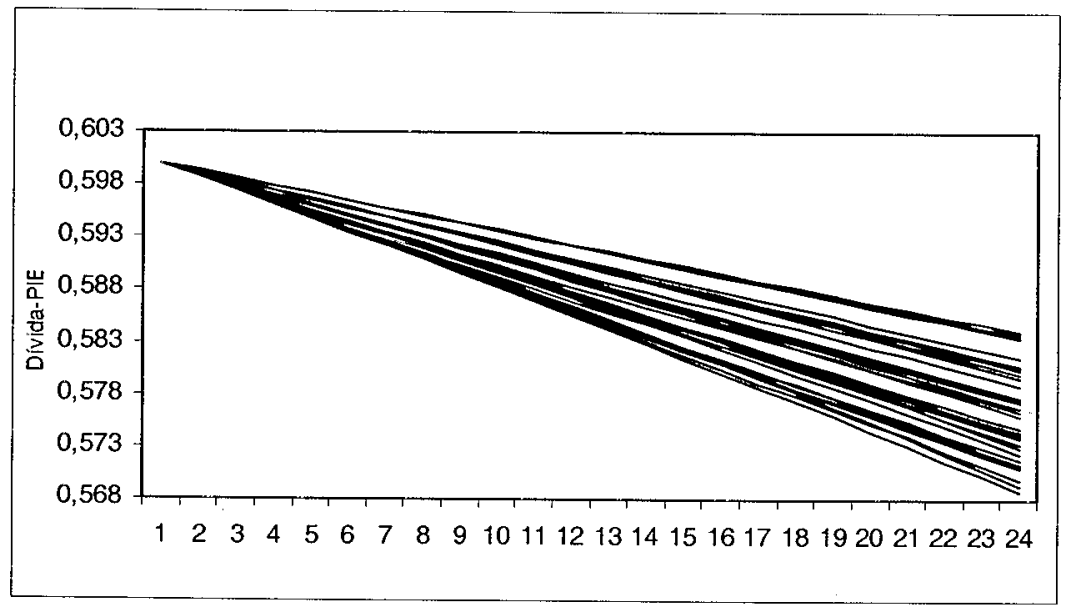

Gráfico 2: Trajetória da dívida indexada à taxa de inflação - diversas estruturas.

Os resultados (Gráfico 3) indicam que, ainda que a taxa de juros possa ser considerada elevada (a taxa de juros real é aproximadamente $12 \%$ ), a relação dívida-PIB se mantém declinante mesmo com uma taxa de inflação que em geral se comporta acima da meta. Assim, mesmo diante de choques na taxa de inflação, a trajetória da relação Dívida-PIB se mantém declinante.

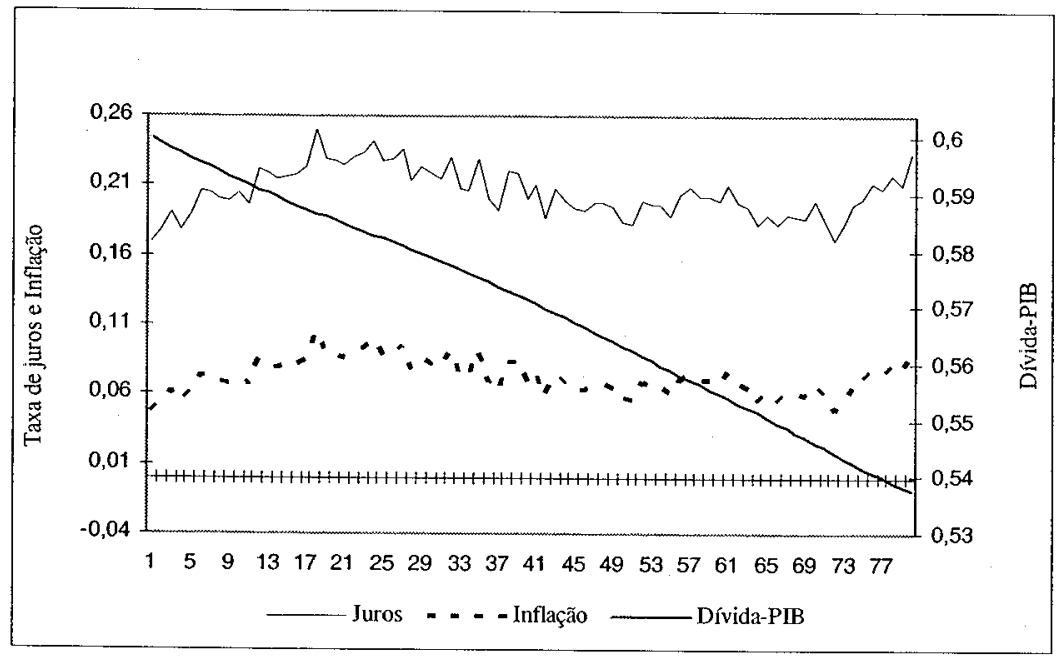

Gráfico 3: Evolução da dívida-PIB e resposta da taxa de juros à choques inflacionários. 


\section{Considerações finais}

A dívida brasileira teve uma considerável elevação no período que sucedeu o Plano Real. Este resultado deve-se a três fatores. O elevado peso de rolagem da dívida, o elevado volume de ajustes patrimoniais realizado e a concentrada estrutura de vencimento desta dívida que é, em sua maioria, de curto prazo e representa um convite para crises financeiras.

$\mathrm{O}$ artigo teve como objetivo mostrar qual estratégia de política macroeconômica pode viabilizar a trajetória da dívida no longo prazo. Foi mostrado que estratégias baseadas em indexação da dívida à taxa de câmbio só são viáveis em regimes de câmbio fixo ou semifixo. No caso de regimes cambiais flutuantes, a indexação via taxa de juros se torna uma política mais adequada.

Este resultado pode ser alterado dependendo do nível de controles de capitais que está introduzido na economia. O resultado desta política é, na prática, estabilizar a taxa de câmbio. A simulação mostrou que esta política pode ser mais adequada representando, assim, um mecanismo superior que a realização de ajustes fiscais. Contudo, a trajetória da dívida não foi estabilizada. Vale ressaltar que os resultados deste cenário são muito voláteis e dependem crucialmente das sensibilidades impostas, e optou-se aqui por um caso intermediário.

A estratégia que se revelou mais adequada foi a alteração da estrutura de indexação da dívida aliada à introdução de controles de capitais. Os resultados desta simulação mostraram que a trajetória da dívida tornou-se declinante sem que fosse necessário um ajuste fiscal que viesse causar prejuízos para a economia.

Deve ser observado que o fato de que a dívida foi inelástica ao superávit primário deve ser visto como um caso particular ao choque implementado. O ponto é que o superávit primário é apenas um instrumento que pode contribuir para estabilizar a dívida. Em muitos casos ele pode não ser o melhor o que ficou comprovado pelos exercícios de simulação realizados.

A administração do governo Lula parece que vem tentando alterar a estrutura de indexação da dívida gradativamente. Em julho de 2004, a parcela da dívida indexada ao câmbio atingiu seu valor, até então, mais baixo da história (14,1\%). Os resultados do artigo mostram que esta estratégia é adequada. Contudo, é desejável aumentar a participação dos índices indexados a índices de preços.

O trabalho simulou, ainda, como a dívida deve se comportar com uma estrutura indexada à taxa de juros e à taxa de inflação diante de diversas composições. Os resultados mostraram-se satisfatórios. A 
dívida, independente da estrutura imposta, mantém-se em uma trajetória descendente. Os resultados independem dos choques sofridos na taxa de inflação.

A proposta de indexar a dívida pública aos índices de inflação tem sido debatida com mais vigor recentemente. A vantagem com este mecanismo é que a luta do banco central em debelar a inflação pode facilitar a tarefa do tesouro. A perda das receitas resultante de uma recessão pode ser compensada com uma rolagem de divida menor.

O primeiro problema com esta proposta é que o governo teme que este mecanismo possa propagar a inflação, conforme sugeriram Bevilaqua e Garcia (2002). O segundo problema é que os agentes privados podem se recusar a aceitar esta política se o grau de confiança na política de administração da dívida for reduzida. Portanto, das medidas propostas, apenas a adoção de controles de captais parecem ser uma solução viável no curto prazo. Alternativamente, o alongamento da dívida bem como a alteração da estrutura de indexação são políticas que devem ser gradativamente executadas no médio prazo.

Pode-se afirmar, ainda, que o ajuste fiscal pode não se constituir na melhor política para a estabilização da dívida pública. A sustentabilidade do arranjo macroeconômico, bem como a compatibilidade deste com a administração da dívida pública, deve ser o grande pilar para a estabilidade das variáveis econômicas.

\section{Referências bibliográficas}

BARCINSKI, A. (1999). Risco de Taxa de Juros e a Dívida Pública Federal no Brasil no PósReal. $2^{\circ}$ lugar no $22^{\circ}$ Prêmio BNDES de Economia.

BEVILAQUA, A. S.; GARCIA, M. (2002). Debt Management in Brazil: Evaluation of the Real Plan and Challenges Ahead. International Journal of Finance and Econornics, jan. v. 7 , n. 1: p. 15-35.

CALVO, G; GUIDOTTI (1990). Indexation and Maturiry of Government Bonds: an Exploratory Model. In: Dornbusch, R.; Draghi, M. (eds.), Public Debt Management: Theory and History. Cambridge: Cambridge University Press.

DE MENDONÇA, H. F. (2004). Dívida Pública e Estabilidade de Preços no Período PósReal: Explorando Relaçōes Empíricas. Estudos Econômicos, v. 34, n. 2. FIPE-USP.

DE PAULA, L. F., OREIRO, J. L., DA SILVA, G. J. C. (2003). Fluxos e Controle de Capitais no Brasil: Avaliação e Proposta de Política. In: SICSÚ, J., OREIRO, J. L. 8 DE PAULA, L. F. (org.). Agenda Brasil: Politicas Econômicas para o Crescimento com Estabilidade de Preços. Manole: Fundação Konrad Adenauer.

GUIDOTTI, P.; KUMER, M. (1991). Domestic Public Debt of Externally Indebted Countries. IMF Occasional Paper, n. 80, June. 
MINELLA, A.; FREITAS, P. S.; GOLDFAJN, 1.; KFOURY, M. Inflation Targeting in Brazil: Lessons and Challenges. Texto para Discussão - Banco Central do Brasil, novembro, 2002. OREIRO, J. L.; PAULA, L. F. de (2003). Uma Estratégia Keynesiana para a Sustentabilidade de Longo Prazo da Dívida Pública. Análise Econômica, v. 40, n. 2. p. 329-338.

PÊGO FILHO, B.; PINHEIRO, M. M. S. (2004). Os Passivos Contingentes e a Dívida Pública no Brasil: Evolução Recente (1996-2003) e Perspectivas (2004-2006). Texto para Discussão IPEA, n. 1007, janeiro.

SICSÚ, J. (2002). Flutuação Cambial e Taxa de Juros no Brasil. Revista de Economia Política, v. 24, n. 3. p. 132-137.

TAMIRISA, N. (2004). Do Macroeconomic Effects of Capital Controls Vary by Their Type? Evidence from Malaysia. IMF working paper, n. 03.

VERSIANI, F. R. (2003). A Dívida Pública Interna e sua Trajetória Recente. Texto para Discussão-Unb, n. 284. 